\title{
Psychological impact of carotid endarterectomy: A review of the studies
}

\section{Impatto psicologico dell'endarterectomia carotidea: una rassegna degli studi}

\author{
Laura Sciarroni, Paola Gremigni, Luciano Pedrini1
}

\begin{abstract}
Psychological impact of carotid endarterectomy: A review of the studies. L. Sciarroni, P. Gremigni, L. Pedrini.

Carotid Endarterectomy (CEA) is a surgical treatment validated to prevent cerebral ischemia, embolism and stroke in patients affected by severe stenosis of the carotid artery. A 1999 systematic review of the literature found controversial results about CEA influence on improvement of post-surgical cognitive performance. Moreover, few studies addressed the issue of the positive effects of CEA on quality of life and depression, reporting also controversial findings. The present review was aimed at considering the last 20 years studies focusing on the effects of CEA on the psychological dimensions. The purpose was to clarify the
\end{abstract}

\begin{abstract}
benefits, in terms of psychological well-being, offered by CEA, besides a reduction of the cardiovascular risk, as well as to have indication to lead further research in this area. Results of the 39 studies considered suggest that, although few studies show cognitive deterioration, most of them show stability with a tendency to improve both in cognitive functions and in other psychological areas. Further research is needed to clarify when it would be appropriate the use of CEA, the characteristics of eligible patients, and psychological as well as physical expected outcomes.
\end{abstract}

Keywords: carotid endarterectomy, cognitive abilities, quality of life, anxiety, depression.

Monaldi Arch Chest Dis 2007; 68: 170-177.

Dipartimento di Psicologia, Università di Bologna.
1 U.O. Chirurgia Vascolare, Ospedale Maggiore di Bologna.

Corresponding author: Paola Gremigni; Dipartimento di Psicologia, Università di Bologna, viale Berti Pichat, 5 - I-40127 Bologna, Italy; E-mail address: paola.gremigni2@unibo.it

\section{Introduction}

Carotid Endarterectomy (CEA) is a surgical intervention of proven effectiveness for the prevention of ischemic and atheroembolic stroke, in patient with severe symptomatic carotid stenosis [1]. In these patients the presence of a neuropsychological syndrome consisting of impairment of cognitive functions such as reasoning, memory and psycho-motor skills has been found [2]. It is important to verify empirically whether CEA influences such functions by reducing, increasing or leaving unchanged the already present deterioration. The influence of CEA on cognitive functioning has been the subject of many studies, but the results are still controversial. A systematic review of the literature underlines conflicting findings in 28 studies, among which 16 reported cognitive improvements after surgery and 12 found no change or, in a few cases, deterioration [3]. Studies of the first type were in prevalence anterior to 1984 , while the other ones were more recent. Concerning the effect of CEA on other relevant psychological aspects, such as depression or quality of life, no current systematic review of the literature is available.

The studies examined by Lunn and colleagues [3] assessed from a minimum of 6 to a maximum of 91 patients undergoing CEA with a variety of char- acteristics such as: unilateral versus bilateral stenosis, right versus left involvement, stroke versus transient ischaemic attacks (TIA) [4-11]. Criteria of exclusion from the study concerned neurological deficit due to TIA or to recent stroke, asymptomatic condition, psychiatric symptoms, other neurological or cognitive pre-surgical deteriorations and stable physical disability $[8,11-15]$. With respect to the study, almost all the studies used a repeated measure design with a first assessment before surgery.

Concerning the use of control groups, 17 studies have used control groups drawn by the general population or among patients undergoing other operations or characterized by various vascular troubles [16]. Matarazzo and colleagues [17] have been the only ones to use a control group with psychotic symptoms, particularly schizophrenic, besides a healthy group and a group of non operated patients with cardiovascular diseases. Different dimensions have been studied as possible incidental factors on the result of the CEA relative to the variation in the cognitive functioning, such as the symptoms preceding the operation, while age and level of education were the demographic factors considered among most of the studies. Only one study assessed the intelligent quotient [18], while another study considered also medical factors such as clamp-time, 
number of strokes and time from the last TIA [13]. Concerning the psychological dimensions evaluated, the number of neuropsychological tests used ranged from 5 up to 34 .

Five studies assessed a limited number of cognitive domains $[6,13,19-21]$, while others used a neuropsychological battery, nevertheless the number of tests used did not seem to influence the reported outcome.

About the results, language and memory were the functions that appeared mostly to improve, some improvements were found also in attention and concentration. [13, 22, 23]. An improvement was found relative to a longer follow-up (median 16 weeks) [6, 13] probably due to the acquired ability of patients to overcome the post-operating troubles in the long period. In some studies the degree of stenosis did not seem to influence the improvement, [24] while in others the patients with stroke improved more than those affected by TIA $[10,25,26]$. Cognitive improvement are generally connected with improvement of cerebral blood flow or with the decreased risk of embolisms. However, from Lunn and colleagues' review [3] emerges that a simple conclusion cannot be reached as regards the impact of CEA on cognitive functioning. Some of the most recent studies did not report improvements $[9,14,27]$, even if such result, according to Lunn and colleagues [3], could derive from methodological limits. The examined studies differ for patients' typology, severity and site of the stenosis contralateral and ipsilateral, use and typology of the control group, number and kind of of evaluation test, type of data analysis, range of the scores obtained in the cognitive performances and times of evaluation. Many studies appear limited by not having detailed important demographic data or remarkable medical characteristics. None of the studies considers the measurement of the cerebrovascular reserve $\left(\mathrm{CO}_{2}\right)$, nor it reports changes of microembolic weight, from the result of the transcranial Doppler performed before, during, and after the intervention. Therefore, Lunn and colleagues [3] suggest giving more attention to methodological factors.

Most of the above studies focused on the effect of CEA on cognitive functioning, while few studies have examined how CEA affects patients' view of their quality of life. For example, a study[28] found that $50 \%$ of the working patients after CEA were forced to an early retirement, manifesting marked reduction in quality of life. This study underlines the importance of preserving the quality of life of patients undergoing CEA, because of its relevant consequences at both individual and society level. Important psychological dimensions related to the perceived quality of life are mood disorders. A review of the literature [29] found some evidence that the co-occurrence of major depression and generalized anxiety disorder is associated with brain lesions following stroke. A recent study focusing on the link between brain ischemia in cerebral areas and the pathogenesis of mood disorders [30], hypothesized that several post-stroke depressive disorders are likely to be the result of specific changes in brain pathology and neurophysiology. From this perspective, it seems to be relevant a study on the effect of CEA on the quality of life and mood of patients, besides its effect on cognitive functioning.
The present paper is aimed at reviewing a) the empirical studies published since March 1998 on the impact of CEA on cognitive functioning to update the review of Lunn and colleagues [3]; b) the studies published since 1970 on the impact of CEA on quality of life and mood, especially depression, to clarify the implication for psychological functioning in patients undergoing CEA.

\section{Methods}

To identify the published studies which examined the impact of CEA on psychological functioning, a computer literature search has been conducted on the database searches PsychInfo, Medline and Enbase. The key words used for the search, together with Carotid endarterectomy, has been the followings: psychology, psychological well-being, psychological disorders, cognition, cognitive diseases, behaviour, quality of life, depression, anxiety.

In the present review two groups of studies have been considered separately: the first one includes studies centred on the impact of CEA on cognitive functioning published since March 1998, therefore subsequently to the review of Lunn and colleagues [3]; the second one includes the studies published since 1970 on the impact of CEA on other psychological dimensions than cognitive functioning. The latter includes also some studies that Lunn and colleagues [3] in their review discussed only for the cognitive aspects.

Every study that has been considered has been classified based on the year of publication, the number of patients undergoing CEA, the control groups included, the time between pre-test and post-test or follow-up, the typology of psychological tests, used and the results of CEA relative to the psychological aspects assessed.

\section{Results}

The search revealed 21 studies, published since March 1998, focused exclusively on the impact of CEA on cognitive functioning and 18 studies, published since 1970, that appraised also other psychological dimensions, particularly quality of life, depression and anxiety.

The characteristics of studies of the first group are presented in Table 1, while those of studies of the second group are presented in Table 2. Most of the 39 examined studies conducted a first assessment before surgery, and repeated the measure from a minimum of 6 hours to a maximum of 8-11 years after surgery. Among them, 16 studies conducted 3 or more follow-ups, while 23 studies used only a pre- and post-operative assessment. In the following paragraphs will be discussed the principal characteristics of the examined studies

\section{Impact of CEA upon the cognitive functioning}

\section{Design}

Among the 21 studies that assessed the impact of CEA on cognitive functioning, only 4 monitored the course of change for at least one year. Among them, the study of Pettigrew and colleagues [31] administered the same tests at 1, 3 and 6 months fol- 
Table 1. - Characteristics of 21 published studies 1998-2006 on impact of CEA on cognitive functioning

\begin{tabular}{lcccccc}
\hline First author & $\begin{array}{c}\text { Year of } \\
\text { publication }\end{array}$ & CEA patients & Control groups & Post-test & Mesuraments & Outcome \\
\hline Heyer & 1998 & 120 & Absent & 5 months & NPB & No change \\
Pettigrew & 2000 & 1.659 & Absent & 5 years & 1 cognitive test & Improvement \\
Coumans & 2000 & 1 & Absent & 4 days & 1 cognitive test & No change \\
Connolly & 2001 & 53 & 41 spinal op. & 2 days & NPB & Decline \\
Sinforiani & 2001 & 65 & 32 neurological disease & 9 weeks & NPB & Improvement \\
Terevnikov & 2002 & 42 & 31 not operated & 2 years & NPB & Improvement \\
Heyer & 2002 & 80 & 25 spinal op. & 1 month & NPB & Decline \\
Kishikawa & 2003 & 23 & 17 healthy & 6 weeks & NPB & No change \\
Aharon-Peretz & 2003 & 22 & 24 healthy, 14 no stenosis & 6 weeks & NPB & No change \\
Pearson & 2003 & 21 & Absent & 13 weeks & NPB & No change \\
Fearn & 2003 & 159 & 29 urological op. & 2 months & NPB & Improvement \\
Di Legge & 2003 & 28 & Absent & 10 weeks & NPB & No change \\
Sahlein & 2003 & 43 & Absent & 2 days & NPB & Decline \\
Kostopanagioutou & 2005 & 70 & Absent & 6 hours & 1 cognitive test & No change \\
Bossema & 2005 & 56 & 46 healthy, & 1 year & NPB & No change \\
Bossema & 2005 & 58 & Absent & 3 months & NPB & Decline \\
Ogasawara & 2005 & 92 & Absent & 6 months & NPB & No change \\
Ogasawara & 2005 & 55 & 92 without edaravone & 1 month & NPB & Improvement \\
Heyer & 2005 & 65 & 46 lumbar op. & 1 month & NPB & Decline \\
Mocco & 2006 & 65 & 56 lumbar op. & 1 month & NPB & Decline \\
Bo & 2006 & 103 & Absent & 3 years & NPB & Decline \\
\hline
\end{tabular}

$\mathrm{CEA}=$ carotid endarterectomy; op.$=$ operation; $\mathrm{NPB}=$ neuro-psychological battery

Table 2. - Characteristics of 18 studies published 1976-2006 on impact of CEA on Quality of Life and mood

\begin{tabular}{|c|c|c|c|c|c|c|}
\hline First author & $\begin{array}{c}\text { Year of } \\
\text { publication }\end{array}$ & CEA patients & Control groups & Post-test & Mesuraments & Outcome \\
\hline Haynes & 1976 & 17 & 9 other operations & 2 months & NPB, Anxiety & Improvement \\
\hline Kelly & 1980 & 35 & 17 other operations & 2 months & NPB, Anxiety, Depression & Improvement \\
\hline Parker & 1983 & 20 & 16 not CEA, 17 other op. & 6 months & NPB, QoL & No change \\
\hline Trudel & 1984 & 50 & Absent & 105 months & QoL & No change \\
\hline De Leo & 1987 & 25 & Absent & 6 months & $\begin{array}{l}\text { NPB, Anxiety, } \\
\text { Depression, QoL }\end{array}$ & Improvement \\
\hline Sirkka & 1992 & 4 & 18 not operated & $8-11$ years & NPB, QoL & No change \\
\hline Iddon & 1996 & 30 & 30 healthy & 3 days & NPB, Depression & No change \\
\hline Vriens & 1998 & 70 & Absent & 3 months & QoL & Improvement \\
\hline Crawley & 2000 & 26 & 20 PTA & 5 months & NPB, Anxiety, Depression & No change \\
\hline Dardik & 2001 & 50 & Absent & 6 months & QoL & Improvement \\
\hline Middleton & 2002 & 162 & Absent & 1 year & QoL & Improvement \\
\hline Oddone & 2002 & 708 & Absent & 6 months & QoL, Illness perception & No change \\
\hline Brand & 2004 & 36 & Absent & 3 months & NPB, Anxiety, Depression & No change \\
\hline Borroni & 2004 & 84 & Absent & 3 months & NPB, Depression & Improvement \\
\hline Lloyd & 2004 & 100 & Absent & 6 months & $\begin{array}{l}\text { NPB, Anxiety, } \\
\text { Depression, QoL }\end{array}$ & No change \\
\hline McCarty & 2004 & 176 & Absent & 1 month & NPB, Anxiety & Improvement \\
\hline Pearson & 2005 & 39 & Absent & 1 month & Anxiety, QoL & No change \\
\hline Bossema & 2005 & 51 & Absent & 1 year & NPB, QoL & Improvement \\
\hline
\end{tabular}

CEA = carotid endarterectomy; PTA = percutaneous transluminal angioplasty; NPB = neuro-psychological battery; QoL = quality of life 
low-up after surgery for 5 years, but it failed to assess the cognitive performance before surgery. Terevnikov and colleagues [32] administered the tests 7-10 days after surgery, at 1 month follow-up and, than every 6 months for 2 years; Bossema and colleagues [33] performed two post-operative assessments at 3 months and one year, and the most recent study of Bo and colleagues [34] used a 3 years post-operative follow-up. In most studies (13/21, $62 \%$ ) the follow-up period ranged between few days to 6 months [35-47], while 4 studies measured the cognitive performance immediately after CEA (between 6 hours and 4 days) [48-51]. It is interesting to notice, as Table 1 points out, that a decline has been found especially in studies that measured the cognitive performance, few days after surgery or within one month from it $[37,46,47,49,50]$, while in studies with a longer follow-up improvement seems to prevail $[31,32,40,46]$, made exception for a recent study [34] that reveals a decline in patient with left symptomatic stenosis. This tendency confirms the result of the previous review [3].

\section{Patient characteristics}

The number of subjects undergoing CEA is between 1 and 1659 patients. Clinical details included symptomatic or asymptomatic condition, unilateral or bilateral stenosis, and degree of lesion, side of involvement, proportion of strokes or TIA. Demographic variables included age, gender and years of education. Surgery details included type of used anaesthesia which has been specified in 8 studies [35, $37,40,44-46,49,50]$, of which 7 reported the use of general anaesthesia and one local anaesthesia [40], while only 5 [33, 38, 46, 49-51] specified the anaesthetic used. Moreover, 3 studies [40, 46, 47] reported to have used selectively a shunt and one [38] reported to use it routinely. 4 studies $[33,36,39,50]$ considered the possibility of using the right hand or the left; only 3 studies $[33,50,51]$ specified the duration of the operation; 4 studies $[35,46,50,51]$ specified the clamping-time; 5 studies [34, 35, 39, 44, 50, 51] considered specific clinical characteristics of patients, such as smoking, diabetes, hyperlipidemia, hypertension and hypercholesterolemy; 2 studies [42, 49] pointed out the level of S100B; 1 study [46] considered the presence of the APOE-epsilon 4 allele; finally 1 study [47] considered the level of the leucocytes.

Exclusion criteria. Most of the authors established specific criteria of exclusion that allowed the generalization of the results. The more recurrent criteria concerned the missed consent to participate in the study, complications (stroke etc.) peri- and postoperative, neurological symptoms, bio-medical risk factors, degree of stenosis $<70 \%$, and relevant medical problems.

Characteristics of control groups. Among the 21 studies, 11 used a control group [32, 33, 36-39, 41, 45-48]. The control groups included healthy subjects $[33,38,39]$, as well as patients undergoing other operations [33, 36, 39, 41, 46, 47, 49]. One study [44] used as a control group 92 patients to which edaravone was not administered during surgery, another [32] used 32 patients not submitted to CEA for refusal or for side effects, and one study used patients with neurological illness [36].
Measures. To evaluate the cognitive performance numerous and diversified neuropsychological tests have been used. Only 3 studies [31, 48, 51] used a single test of cognitive ability, while the majority used a battery including several neuropsychological tests. The Mini-Mental State Examination [52] has been used in 6 studies with the intent to appraise short-term and long-term memory, praxis ability, spatial and temporal orientation, computational ability, attention and language [31, 34, 38, 39, 42, 48]. The Rey Complex Figures [53] has been used in 8 studies [37, 39, 42, 44, 46, 47, 49, 50] to measure perceptive organization, visuo-spatial and other functions of the right hemisphere. The Trail Making Test parts Á. and B [54] developed to assess understanding and attention processes has been used in 8 studies [33, 39, 40, 43, 46-48, 55]. The Controlled Oral Word Association Test [56], to appraise oral fluidity and functions of the left hemisphere, has been used in 7 studies [37, 40, 46, 47, 49, 50]. Finally the Grooved Pegboard [57] has been used in 3 studies [39, 48, 55] to assess the manual ability.

Cognitive change. Results of studies on the cognitive change after CEA were controversial. Among the 21 studies some did not found any cognitive change $[31,37,39,42,51,55]$, others revealed the presence of some not statistically significant changes, [33, 35, 48]. Other studies found a different course of the cognitive change relative to the different length of time between pre- and post-test $[32,35$, $36,38,43-44,48]$. For example, Heyer and colleagues [33] administered to 120 patients with carotid stenosis a battery of neuropsychological tests before discharge from the hospital and at one and 5 months follow-up. At the first assessment, $80 \%$ of the patients showed impairments in one or more tests, with a greater decline in memory, but at the second follow-up the proportion of improvements appeared increased, especially in the motor tests. Some studies found improvements only in specific areas, and a stable course or decline in others [32, 33, $36,41,49]$. Other studies found different courses relative to specific characteristics of patients $[38,42$, 49]. For example, Kishikawa and colleagues [38] found worse results in patients with cerebrovascular lesions, while patients with serious stenosis showed improvements. Connolly and colleagues [49] found a decline after CEA in patients with cognitive deficit, especially in perception and visuo-spatial and motor organization, while patients without deficit appeared improved in linguistics abilities, perceptive, visual and motor organization. Some studies pointed out differences in some measured abilities before the operation relative to the characteristics of patients [39, 40, 48]. For example, Pearson and colleagues [40] found lower competencies in the oral ability, visual, linguistic understanding and mental flexibility in patients with stroke, in comparison to the others.

Specific cognitive abilities appeared in some studies subject to post-operative deterioration [34, $37,43,44,47]$; the most recurrent decline being found in motor and praxis-constructive abilities [37, 49]. Bo and colleagues [34] underlined, at 3 years from CEA, decline in 29 patients with symptomatic left stenosis among 103 total patients, of which 50 with symptomatic and lanthanic left stenosis. Moc- 
co and colleagues [47] reported cognitive deterioration in $26 \%$ of the patients one day after CEA. Heyer and colleagues [37] reported a general decline in cognitive functioning, especially in women, and an increase of pain In a following study, Heyer and colleagues [46] found cognitive deterioration after CEA in $42 \%$ of patients carriers of the APOE-epsilon 4 allele, compared to the not carriers, of which only $5 \%$ showed analogous deteriorations. The authors suggested that diabetes and obesity, in association with the presence of such allele predisposed to the cognitive deterioration following CEA. Ogasawara and colleagues [45] suggested that a treatment with edaravone can prevent the development of cognitive post-operative deterioration. In their study at one month follow-up only one, among the 55 patients treated with edavarone before the clamping showed a cognitive decline, while in the control group a decline involved $12 \%$ of patients.

Concerning cognitive improvements, some studies $(5 / 21,24 \%)$ reported positive change after CEA on memory and attention [31, 32, 36, 41, 45, 58]. Among these, Fearn and colleagues [41] reported that patients with worse circulation improved more than the others, especially in attention. Other studies underlined improvements in language and in visual memory [32]. Coumans and McGrail [48] examined the case of a patient with interesting results. A woman with bilateral stenosis of the carotid, with serious depression and delirium, after CEA showed a disappearance of any suicidal ideation, a dramatic reduction in depressive and psychotic symptoms, and two months later she returned to her normal daily activities. After the following operation of the contralateral carotid, the patient did not report any psychological symptom and such result was maintained at one year follow-up. The authors of this study were the first ones to have noticed psychotic symptoms in presence of carotid stenosis and they attributed their cause to the potential damage of the limbic activity, following the reduction blood to the brain.

\section{Impact of CEA on quality of life and mood}

Among the studies on impact of CEA on psychological dimensions other than cognitive functioning, published between 1970 to 2006, 12 considered cognitive ability together with other psychological variables, such as anxiety, depression, satisfaction, and quality of life $[8,55,58-67]$; 4 studies focused only on quality of life [30,68-70]; one on quality of life and anxiety [71] and one on quality of life and perception of illness [72]. Altogether quality of life was evaluated in 11 studies on $18(61 \%)$ [30, 60-62, 65, 67-72], anxiety in 7 (39\%) studies $[8,55,59,64-66$, 71] and depression in $7(39 \%)[8,55,58,61,63-65]$.

Design. Part of the studies on the impact of CEA on psychological dimensions $(5 / 18,28 \%)$ assessed these dimensions in a length of time between pre- and post-operation from a few days - to two months [8, $59,63,66,71] ; 9$ studies used a 3-6 months follow-up $[55,57,60,61,64,65,68,69,72]$, and 4 studies used a one year and more follow-up [30, 62, 67, 70]. For example, Sirkka and colleagues [62] used a post-operative assessment of both cognition and quality of life between 8 and 11 years after surgery
Patient characteristics. The number of subjects undergoing CEA ranged between 4 and 708 patients. Most of the studies collected information on symptomatic or asymptomatic condition, on degree and side of the stenosis, on strokes, TIA and cerebral lesions. Demographic variables included age, gender and level of education. Other variables investigated were the type of used anaesthesia $[59,65]$; the selectively use of shunt $[61,64,67,68]$; the use of the right or the left hand [64]; the duration of intervention [59]; the clamping-time [59, 64]; specific clinical characteristics of patients, [64, 68, 69, 72], intelligence quotient [59], and patients' race [72].

Exclusion criteria. Interesting criteria of exclusion, but less frequent in the 1998-2006 studies, were claustrophobia and other psychic disorders, visual or language deficit physical deficit, contralateral stenosis, cerebrovascular diseases, serious cardiovascular illness, female gender, left-hand, less than 5 years of school education, communication difficulty with the health personnel, excessive residence distance from the hospital, and trauma following the death of a dear person.

Characteristics of the control groups. Among the studies examined only 6 used a control group $[8$, $55,59,60,62,63]$; of them 3 studies included patients undergoing other treatments (PTA or other vascular operations) $[8,55,60]$ and only a study used a control group of healthy subjects [63].

Measures. To assess depression, anxiety and quality of life, numerous and different tests have been used. Anxiety was assessed with the State-Trait Anxiety Inventory [73] in 5 studies [8, 55, 59, 66, 71], While the other studies used the Hospital Anxiety Depression Staircases [74] and the Well Being Questionnaire [75]. Depression was assessed with the Zung self rating Depression Scale [61, 76], the Beck Depression Inventory [77] [55, 63], the Geriatric Depression Staircases [78] and the Mini Mult Test [79]. Quality of life was measured with the SF-36 [69] in 5 studies $[65,67,69-71]$ or with its reduced form, the SF-12 [72, 81]. Other studies used the Sickness Impact Profile [60, 68, 81], the Jachuck's Quality of Life Impairment Staircases [83] and the Carey and Posavac Level of Rehabilitation Scale [84].

Quality of life and mood change. Studies on quality of life, depression and anxiety reported a general tendency to stability or to improvement following CEA, but studies not reporting positive statistically significant change in these dimensions were 9 on $18(50 \%)$ [30, 55, 60, 62-65, 71, 72]. Among these, Trudel and colleagues [30] recommended the activation of programs of post-operative rehabilitation to preserve or to increase patient quality of life. A relevant improvement, together with some signs of stability was reported in 9 studies $[8,58,59,61,65-$ $70]$ in anxiety, depression, and quality of life. However, we cannot conclude that these improvements were necessarily following CEA. For example, one study [8] comparing patients candidate to CEA to a control group using a peri- and post- operative assessment anxiety and depression reported a tendency to improve in both the groups. Vriens and colleagues [68] reported some improvements in quality of life, but a no impact of CEA on study outcome was the prevailing trend. Haynes and colleagues [59] sus- 
tained that following CEA numerous patients reduce anxiety and sense of confusion as a consequence of improvement obtained in understanding, perception and motor skills. One Italian study [61] reported an improvement in quality of life and in global health status perceived by patients, while depressive symptoms remained unchanged. Dardik and colleagues [69] found a significant improvement in quality of the life in patients lanthanic undergoing CEA and associated it to the patients' trust of the received operation. Another study [66] found that CEA performed with local anaesthesia was not associated with any increased anxiety, was tolerated by most patients and was associated with a positive perception of recovery. Bossema and colleagues [67] reported a post-operative improvement in the sense of vitality and in perception of physical and mental health. Another study [58] mentioned a reduction of the post-operative depression, beyond the reported improvement in cognitive functioning in patients with mild vascular cognitive impairment, without deepening the discussion on this specific issue. A recent study [70] has evaluated the long-term incidence of mortality after CEA, considering the course of quality of life. It emerged that 1 year after the surgery, $57 \%$ of patients reported not having perceived any change in their quality of life. Therefore the study suggested the implementation of rehabilitation programs targeted at improving the quality of life of patients before discharge from the hospital. It is relevant to underline that none of the 18 studies examined in this review reported significant decline in the psychological dimensions considered

\section{Conclusion}

Among the 21 studies, conducted between 1998 and 2006, focused on the impact of CEA on cognitive functioning, 7 reported a post-operative cognitive decline, 9 did not report any significant change, while 5 showed a relevant improvement.

The most recent studies, following the review of Lunn and colleagues [3], underlined a persistent contrast in the results. For example, a post-operative improvement in the cognitive function has been reported by Terevnikov, Burkin, Dudanov and Subbotina [32] only when the operation was performed in the first stadium of cerebral ischemia. An Italian study [36] reported a post-operative improvement only in memory and attention, that was maintained at three months, and a longitudinal study [41] reported a two months follow-up improvement in attention. On the opposite, another recent study reported a decline in the cognitive functions in $28 \%$ of patients the day after CEA, that persisted unchanged after 30 days [24]. Thus, findings appear still conflicting and do not allow reaching a clear conclusion regarding the impact of CEA on cognitive functioning. The main reason of this contrast is probably due to the great difference of the studies in many methodological factors such as type of patients and control groups, clinical and demographic characteristics of patients, timing of assessment and range of different tests used. Further research is needed with more attention to such methodological factors. Concerning the impact of CEA on psychological dimensions other than cognitive func- tioning, half of the studies published between 1970 and 2006 reported an improvement, especially in quality of life, the remaining showed results of substantial stability, without any decline in these dimensions after CEA. Most of the improvements concerned the quality of life and anxiety, while depression seemed to remain substantially unchanged.

The positive trend of these studies points out that CEA can offer to the patients an improvement that is not circumscribed to the cognitive area, but may concern the sense of perceived general well-being of the individual. The area of quality of life and perceived well-being has assumed an important role promoted by the WHO, nevertheless it has been scarcely investigated in some medical settings. The positive results reported by some of the studies performed in this area suggest putting more attention, in future research, to the emotional aspects of patients undergoing CEA, as well as to their representation of illness and of the impact of surgery on health and daily life.

\section{Riassunto}

L'endarterectomia carotidea (CEA) è un intervento chirurgico per la prevenzione di ischemie, embolie e ictus in pazienti con grave stenosi dell'arteria carotidea. Una rassegna sistematica della letteratura del 1999 evidenzia risultati contrastanti riguardo all'influenza della CEA sul miglioramento della performance cognitiva in fase post-operatoria. Sporadici studi affrontano, inoltre, la questione dei possibili effetti positivi della CEA sulla qualità di vita e sulla depressione dei pazienti operati, riportando risultati contrastanti anche in questo ambito. La presente rassegna prende in considerazione gli studi empirici dedicati agli effetti della CEA sulle dimensioni psicologiche condotti negli ultimi 20 anni per cercare di chiarire il beneficio, in termini di benessere psicologico, che la CEA può offrire ai pazienti, oltre alla riduzione del rischio ischemico. I risultati dei 39 studi considerati indicano che, mentre ridotto è il numero di studi che rilevano peggioramenti cognitivi, numerosi sono quelli che segnalano stabilità con tendenza al miglioramento sia in ambito cognitivo, sia in altre dimensioni psicologiche. Studi più sistematici consentirebbero di chiarire quando avvalersi della CEA, con quale tipologia di pazienti e quali effetti fisici e psicologici attendersi.

Parole chiave: endarterectomia carotidea, abilità cognitive, qualità di vita, ansia, depressione.

\section{References}

1. Scottish Intercollegiate Guidelines Network. Management of Patients with Stroke II: Management of Carotid Stenosis and Carotid Endarterectomy. A National Clinical Guideline recommended for use in Scotland. Edimburgh: S.I.G.N., 1999, Publication n. 14.

2. Bakker FC, Jennekens-Dcinkel KA. Cognitive disorders in patients with occlusive disease of the carotid artery: a systematic review of the literature. J Neurol 2000; 247: 669-676.

3. Lunn S, Crawley F, Harrison MJ, Brown MM, Newman SP. Impact of carotid endarterectomy upon cognitive functioning. A systematic review of the literature. Cerebrovasc Dis 1999; 9: 74-81. 
4. Williams M, McGee GF. Psychological study of carotid occlusion and endarterectomy. Arch Neurol 1964; 10: 293-297.

5. Drake WE, Baker M, Blumenkrantz J, Dahlgren H. The quality and duration of survival in bilateral carotid occlusive disease. A preliminary survey of the effects of thromboendarterectomy. Cerebral Vascular Disease 1968; 242-259.

6. Wilson SE, Bennion RS, Owens I. Effect of carotid endarterectomy on postoperative psychological test performance. J Cardiovasc Surg 1983; 24-428.

7. Goldstein SG, Kleinknecht RA, Gallo AE. Neuropsychological changes associated with carotid endarterectomy. Cortex 1970; 6: 308-322.

8. Kelly MP, Garron DC, Javid H. Carotid disease, carotid endarterectomy, and behaviour. Arch Neurol 1980; 37(12): 743-748.

9. Boeke S. The effect of carotid endarterectomy on mental functioning. Clin Neurol Neurosurg 1981; 83: 209-217.

10. Hemmingsen R, Mejsholm B, Vorstrup S, Letter J, Engell $\mathrm{HC}$, Boysen G. Carotid surgery, cognitive function, and cerebral blood flow in patients with transient ischemic attacks. Ann Neurol 1986; 20(1): 13-19.

11. Casey JE, Ferguson GG, Kimura D, Hachinski VC. Neuropsychological improvement versus practice effect following unilateral carotid endarterectomy in patients without strike. J Clin Exp Neuropsychol 1989; 11(4): 461-470.

12. Horne JP, Royle JP. Cognitive changes after carotid endarterectomy. Med J Aust 1974; 1: 316-318.

13. Jacobs LA, Ganji S, Shirley JG, Morrell RM, Brinkman SD. Cognitive improvement after extra-cranial reconstruction for the low flow endangered brain. Surgery 1983; 683-687.

14. Dienier HC, Hamster W, Seboldt H. Neuropsychological functions after carotid endarterectomy. Eur Arch Psychiatry Neurol Sci 1984; 234(1): 74-77.

15. Parker JC, Granberg BW, Nichols WK, Jones JG, Hewett JE. Mental status outcomes following carotid endarterectomy: a six-month analysis. J Clinic Neuropsychol 1983; 5(4): 345-353.

16. van den Burg W, Saan RJ, Van Zomeren AH, Boontje AH, Haaxma R, Wichmann TE. Carotid endarterectomy: does it improve cognitive or motor functioning? Psychol Med 1985; 15(2): 341-346.

17. Matarazzo RG, Matarazzo JD, Gallo AE, Wiens AN. IQ and neuropsychological changes following carotid endarterectomy. J Clin Neuropsychol 1979; 1: 97-116.

18. Duke RB, Bloor BM., Nugent GR, Majzoub HS. Changes in performance on Wais, Trail making test and finger tapping test associated with carotid artery surgery. Percept Mot Skills 1968; 26: 399-404.

19. Owens M, Pressman M, Edwards AE, Toutellotte W, Rose JG. The effect of small infarets and carotid endarterectomy on postoperative psychologic test performance. J Surg Res 1980; 28: 209-216.

20. Brinkman SD, Braun P, Ganji S, Morrell RM, Jacobs LA. Neuropsycological performance one week after carotid endarterectomy reflects intra-operative ischemia. Stroke 1984; 15: 497-503.

21. Bennion RS, Owens ML,Wilson SE. The effect of unilateral carotid endartertectomy on neuropsychological test performance in 53 patients. J Cardiovasc Surg 1985; 26(1): 21-6.

22. Perry PM, Drinkwater JE, Taylor GW. Cerebral function before after carotid endarterectomy. Br Med J 1975; 215-216.

23. King GD, Gideon DA, Haynes CD, Dempsey RL, Jenkins EW. Intellectual and personality changes associated with carotid endarterectomy. J Clin Psychol 1977; 33(1): 215-220.

24. Horne JP, Royle JP. Cognitive changes after carotid endarterectomy. Med J Aust 1974; 1: 316-318.

25. Bornstein RA, Benoit BG, Trites RL. Neuropsychological changes following carotid endarterectomy. Can $J$ Neurol Sci 1981; 8(2): 127-32.
26. Mononen H, Lepojarvi M, Kallanranta T. Early neuropsychological outcome after carotid endarterectomy. Eur Neurol 1990; 30(6): 328-333.

27. Williams M, McGee GF. Psychological study of carotid occlusion and endarterectomy. Arch Neurol 1964; 10: 293-297.

28. Trudel L, Fabia J, Bouchard JP. Quality of life of 50 carotid endarterectomy survivors: A long-term follow-up study. Arch Phys Med Rehabil 1984; 65(6): 310-312.

29. Robinson RG, Starkstein SE. Current research in affective disorders following stroke. J Neuropsychiatry Clin Neurosci 1990; 2(1): 1-14.

30. Spalletta G, Bossu P, Ciaramella A, Bria P, Caltagirone C, Robinson RG. The etiology of poststroke depression: a review of the literature and a new hypothesis involving inflammatory cytokines. Mol Psychiatry 2006; 11(11): 984-991.

31. Pettigrew LC, Thomas N, Howard VJ, Veltkamp R, Toole JF. Low Mini-mental status predicts mortality in asymptomatic carotid arterial stenosis. Asymptomatic carotid Atherosclerosis Study investigators. Neurology 2001; 2; 55(1): 30-34.

32. Terevnikov VA, Burkin MM, Dudanov IP, Subbotina NS. Dynamics of higher mental functions in surgical therapy of internal carotid artery stenosis. Zh Nevrol Psikhiatr Im S S Korsakova 2002; 102(4): 21-25.

33. Bossema ER, Brand N, Moll F, Ackerstaff RG, van Doornen LJP. Does carotid endarterectomy improve cognitive functioning? J Vasc Surgery 2005; 41: 775-781.

34. Bo M, Massaia M, Speme S, Cappa G, Strumia K. Risk of Cognitive Decline in Older Patients After Carotid Endarterectomy: An Observational Study. J Am Geriatr Soc 2006; 54: 932-936.

35. Heyer EJ, Adam DC, Solonon RA, Todd G J, Quest DO, McMahon DJ, et al,. Neuropsychometric change in patients after endarterectomy. Stroke 1998; 29(6): 1110-5.

36. Sinforiani E, Curci R, Fancellu R, Facchinetti P, Mille T, Bono G. Neuropsychological changes after carotid endarterectomy. Funct Neurol 2002; 16(4): 329-36.

37. Heyer EJ, Sharma R, Rampersad A, Winfree CJ, Mack WJ, Solomon RA, et al,. A controlled prospective study of neurological dysfunction following carotid endarterectomy. Arch Neurol 2002; 59(2): 217-26.

38. Kishikawa K, Kamouchi M, Okada Y, Inoue T, Ibayashi S, Iida M. Effect of endarterectomy on cerebral blood flow and neuropsychological test performance in patients with stenosis. J Neurol Sci 2003; 19-24.

39. Aharon-Perez J, Tormer R, Gabrieli I., Aharonov D, Nitecki S, Hoffman A. Cognitive performance following endarterectomy in asymptomatic severe carotid stenosis. Eur J Neurol 2003; 10: 525-528.

40. Pearson S, Maddern G, Fitridge R. Cognitive performance in patients after carotid endarterectomy. $J$ Vasc Surg 2003; 38: 1248-53.

41. Fearn SJ, Hutchinson S, Riding G, Hill-Wilson G, Wesnes K, McCollum CN. Carotid endarterectomy improves cognitive function in patients with exhausted cerebrovascular reserve. Eur J Vasc Endovasc Surg 2003; 26(5): 529-36.

42. Di Legge S, Di Pietro V, Di Stani F, Perna R, Gattuso R, Reale MG, et al,. Carotid endarterectomy and gliofibrillar S100b protein release. Neurol Sci 2003; 24: 351-356.

43. Bossema ER., Brand N, Moll F, Ackerstaff RGA, van Doornen LJP. Perioperative micro-embolism is not associated with cognitive outcome three months following carotid endarterectomy. Eur J Vasc Endovasc Surgery 2005; 29: 262-268.

44. Ogasawara K, Yamadate MDK, Kobayashi MM, Endo H, Fukuda T, Yoshida MDK, et al,. Postoperative cerebral hyperfusion associated with impaired cognitive function in patients undergoing carotid endarterectomy. J Neurosurg 2005; 102: 38-44.

45. Ogasawara K, Yamadate MDK, Kobayashi MM, Endo H, Fukuda T, Yoshida MDK, et al,. Effects of the free radi- 
cal scavenger, edaravone, on the development of postoperative cognitive impairment in patients undergoing carotid endarterectomy. Surg Neurol 2005; 64: 309- 314.

46. Heyer EJ, Wilson BS, Sahlein DH, Mocco J, Williams $\mathrm{SC}$, Sciacca R, et al,. APOE-4 predisposes to cognitive dysfunction following uncomplicated carotid endarterectomy. Neurol 2005; 65: 1759-1763

47. Mocco J, Wilson DA, Ducruet AF, Komotar RJ, Mack WJ, Connolly ES. Elevations in preoperative monocyte count predispose to acute neurocognitive decline after carotid endarterectomy for asymptomatic carotid artery stenosis. Stroke 2006; 37(1): 240-242.

48. Coumans JV, McGrail KMD. Psychiatric presentation of carotid stenosis. Surgery 2000; 127: 713-5.

49. Connolly ES, Winfree CJ, Rampersad A, Sharma BA, Mack WJ, Mocco J, et al. Serum S100B protein levels are correlated with subclinical neurocognitive declines after carotid endarterectomy. Neurosurg 2001; 49: 1076-1082.

50. Sahlein D, Heyer E, Rampersad A, Winfree C, Solomon $\mathrm{R}$, Benvenisty AI et al. Failure of intra-operative jugular bulb S-100B and neuron-specific Enolase sampling to predict cognitive injury after carotid endarterectomy. Neurosurg 2003; 53: 1243-1250.

51. Kostopanagiotou G, Markantonis SL, Polydorou M, Pandazi A, Kottis G. Recovery and cognitive function after fentalyn or remifentalyn administration for carotid endarterectomy. J Clin Anesth 2005; 17(1): 16-20.

52. Folstein MF, Folstein SE, McHugh PR. Mini-mental State. A practical method for grading the cognitive state of patients for the clinician. J Psychiatr Res 1975; 12(3): 189-198.

53. Loring DV, Martin RV, Meador KJ, Lee GP. Psychometric construction of the Rey-Osterrieth complex figure: Methodological considerations and interrater reliability. Arch Clin Neuropsychol 1990; 5(1): 1-14.

54. Reitan RM. The validity of the Trail Making Test as an indicator of organic brain damage. Percept Motor Skills 1958; 271-276

55. Crawley F, Stygall J, Lunn S, Harrison M, Brown M, Newman S. Comparison of microembolism detected by transcranial Doppler and neuropsychological sequelae of carotid surgery and percutaneous transluminal angioplasty. Stroke 2000; 31: 1329-34.

56. Benton AL, Hamsher K, Sivan AB. Multilingual aphasia examination (3rd ed.), Iowa City, Iowa, AJA Associates, 1983.

57. Heaton RK, Grant I, Matthews C. Comprehensive norms for an expanded Halstead-Reitan Battery: Demographic corrections, research findings, and clinical applications, Lutz, FL, Psychological Assessment Resources, Inc. 1983.

58. Borroni B, Tiberio G, Bonardelli S, Cottini E, Facheris M, Akkawi Net al,. Is mild vascular cognitive impairment reversible? Evidence from a study on the effect of carotid endarterectomy. Neurol Res 2004; 26: 594-597.

59. Haynes CD, Gideon DA, King GD, Dempsey RL. The improvement of cognition and personality after carotid endarterectomy. Surgery 1976; 80(6): 699-704.

60. Parker JC; Granberg BW, Nichols BW, Jones JG, Hewett JE. Mental Status outcomes following carotid endarterectomy: A six-month analysis. J Clin Neuropsychol 1983; 5(4): 345-353.

61. De Leo D, Serraiotto L, Pellegrini C, Magni G, Franceschi L, Deriu GP. Outcome from carotid endarterectomy. Neuropsychological performances, depressive symptoms and quality of life: 8-month follow-up. Int J Psychiatry Med 1987; 17(4): 317-25.

62. Sirkka A, Salenius P, Portin R, Nummenmaa T. Quality of life and cognitive performance after carotid endarterectomy during long-term follow-up. Acta Neurol Scand 1992; 85(1): 58-62.

63. Iddon JL, Sahakian BJ, Kikpatrick PJ. Uncomplicated carotid endarterectomy is not associated with neuropsychological impairment. Pharmacol Biochem Behav. 1997; 56(4): 781-7.
64. Brand N, Bossema ER, van Ommen M, Moll FL, Ackerstaff RGA. Left or right carotid endarterectomy in patients with atherosclerotic disease: Ipsilateral effects on cognition? Brain Cogn 2003; 54: 117-123.

65. Lloyd AJ, Hayes PD, London AJ, Bell PR, Naylor AR. Does carotid endarterectomy lead to a decline in cognitive function or health related quality of life? J Clin Exp Neuropsychol 2004; 26(6): 817-825.

66. McCarthy RJ, Trigg R, John C, Gough MJ, Horrocks M. Patient satisfaction for carotid endarterectomy performed under local anaesthesia. Eur J Vasc Endovasc Surg 2004; 27, 654-659.

67. Bossema ER, Brand AN, van Ommen M, Moll FL, Ackerstaff van Doornen LJ. Effect of carotid endarterectomy on patient evaluations of cognitive functioning and mental and physical health. Ann Vasc Surg 2005; 19(5): 673-677.

68. Vriens EM, Post MW, Jacobs HM, van Huffelen AC, Eikelboom BC. Change in health-related quality of life after carotid endarterectomy. Eur J Vasc Endovasc Surg, 1998; 16(5): 395-400.

69. Dardik A, Minor J, Watson C, Hands LJ. Improved quality of life among patients with symptomatic carotid artery disease undergoing carotid endarterectomy. J Vasc Surg 2001; 33(2): 329-33.

70. Middleton S, Donnelly N, Harris J, Lusby R, Ward J. Audit of long term mortality and morbidity outcomes for carotid endarterectomy. Aust Health Rev 2002; 25, 81-91.

71. Pearson S, Maddern GJ, Fitridge R. The role of pre-operative state-anxiety in the determination of intra-operative neuroendocrine responses and recovery. Brit J Health Psychol 2005; 10(Pt 2): 299-310.

72. Oddone Z, Horner RD, Johston MD, Stechuchak K, McIntyre L, Ward A, et al. Carotid endarterectomy and race. Do clinical indications and patient preferences account for differences? Stroke 2002; 33: 2936-2943.

73. Spielberger CD, Gorsweh RL, Glushene RL. The statetrait anxiety inventory, Palo Alto, CA, Consulting Psychologists Press 1968.

74. Zigmond AS, Snaith RP. The hospital anxiety and depression scale. Acta Psychiat Scand 1983; 67, 361-370.

75. Pouwer F, Snoek FJ, Van der Ploeg HM, Heine RJ, Brand AN. A comparison of the well-being questionnaire (WBQ) and the diabetes treatment satisfaction questionnaire (DTSQ). Qual Life Res 1998; 7: 33-38.

76. Zung WW. A self-rating depression scale. Arch Gen Psychiat 2000; 12(1): 63-70.

77. Beck AT. An Inventory for measuring depression. Arch Gen Psychiat 1961; 4: 561-571.

78. Sheikh JI, Yesavage JA. Geriatric Depression Scale (GDS): Recent evidence and development of a shorter version. In: Brink TL, ed. Clinical Gerontology: A guide to assessment and intervention. Binghamton, NY, Haworth, Press Inc. 1986: 165-173.

79. Garner ZLA, Leandro MA. Mini-Mult 82: Review and standardization of short version of the MMPI questionnaire. Acta Psiquiatr Psicol Am Lat 1993; 39(1): 58-62.

80. Ware Jr, Sherbourn CD. The MOS 36-item short-form health survey (SF-36). Med Care 1992; 30: 473-483.

81. Ware Jr, Kosinski M, Keller, SD. A 12-Item Short-Form Health Survey: Construction of scales and preliminary tests of reliability and validity. Med Care 1996; 34(3): 220-233.

82. Bergner M, Bobbitt R, Pollard W, Martin D, Gilson B. The Sickness Impact profile: Validation of a health status measure. Med Care 1976; 14, 57-67.

83. Jachuck SJ. 1982. The effect of hypotensive drugs on the Quality of Life. J Roy Coll Fam Physic 1982; 37: 116-119.

84. Carey RG, Posavac, EJ. Program evaluation of a physical medicine and rehabilitation unit: New approach. Arch Phys Med Rehabil 1978; 59: 330-338.

\section{ABBREVIATIONS}

$\mathrm{CEA}=$ Carotid Endarterectomy

TIA $=$ Transient Ischemic Attack 